\title{
Bárbara bela
}

José Américo Miranda Universidade Federal de Minas Gerais

Resumo: Este artigo analisa o poema 21 (classificação de Rodrigues Lapa) do poeta árcade Alvarenga Peixoto, mais conhecido por seu primeiro verso - "Bárbara bela". Além de um estudo da estrutura do poema, o texto avalia a pertinência da compreensão do poema durante o Romantismo em relação à sua significação mais importante: a de que a separação entre o poeta e sua Bárbara será irreversivel.

Palavras-chave: Poesia brasileira; Poesia neoclássica; Alvarenga Peixoto

O poeta e a obra

O poeta Alvarenga Peixoto nasceu no Rio de Janeiro, em 1743 ou 1744 - tinha, pois, aproximadamente, a mesma idade de Tomás Antônio Gonzaga. Ambos foram presos, quando contavam cerca de 45 anos de idade, acusados de traição à coroa portuguesa. Manuel Rodrigues Lapa, o mais importante editor do réu de inconfidência, nascido no Rio, mas conduzido pelo destino a São João del Rei, informa que apenas três poemas seus foram publicados em vida:

a) o sonêto dedicado ao Uraguay de José Basílio da Gama, que acompanha o poema na edição de 1769: Entro pelo Uraguay, vejo a cultura; b) o sonêto dedicado à Estátua Eqüestre, em 6 de junbo de 1775: América sujeita, Ásia 
vencida; c) a lira $\mathrm{O}$ retrato (de Marília e não de Anarda) publicada em 1785 no vol. VII da Miscelânea curiosa e proveitosa, sem nome de autor, o que a torna um pouco duvidosa.

Ao todo, reuniu o editor de Alvarenga apenas 33 poemas. Desses, o único do qual existe manuscríto autógrafo é o que traz o número 26 na edição de Lapa: trata-se de uma ode incompleta ao visconde de Barbacena, "Segue dos teus maiores". Esse poema faz parte dos Autos de Devassa como peça de acusação. Quanto à utilização de poesias do autor no processo da Inconfidência, seu advogado de defesa, José de Oliveira Fagundes, também transcreveu um soneto dele ao final das alegações em defesa do réu, "A Paz, a doce Mãe das alegrias" (que traz o número 33 na edição de Lapa) - soneto dirigido à rainha D. Maria I. ${ }^{3}$ Desde então, pelo menos um poema foi acrescentado a sua obra: trata-se do soneto cujo primeiro verso é "Chia de dia pela rua o carro", publicado por Francisco Topa em 1998.

Antes de Rodrigues Lapa (1960), teve Alvarenga Peixoto três outros editores que se esforçaram por lhe reunir a obra dispersa: Januário da Cunha Barbosa (1829-1832), Joaquim Norberto de Sousa Silva (1865) e Domingos Carvalho da Silva (1956).

Januário da Cunha Barbosa foi o primeiro editor do poeta, tendo alcançado a reunião de 20 poemas, dos quais 18 constam também da edição de Lapa. Foram excluídos por este o poema que traz o título "Retrato", cujo primeiro verso é "A minha Anarda", e o poema que tradicionalmente tem sido atribuído à mulher de Alvarenga, Bárbara Eliodora, cujas duas primeiras estrofes vão aqui transcritas:

Meninos, eu vou ditar

As regras do bem viver;

Não basta somente ler,

É preciso ponderar,

Que a lição não faz saber,

Quem faz sábios é o pensar.

Neste tormentoso mar

1. LAPA. Vida e obra de Alvarenga Peixoto, p. LVI. (Grifos do autor.)

2. Cf. LAPA. Vida e obra de Alvarenga Peixoto, p. LVII-LVIII.

3. Cf. Autos de devassa da Inconfidência Mineira, v. 7, p. 154.

4. Cf. TOPA. Quatro poetas brasileiros do periodo colonial-Estudos sobre Gregório de Matos, Basílio da Gama, Alvarenga Peixoto e Silva Alvarenga, p. 50.

5. Cf. MIRANDA. O Parnaso brasileiro, de Januário da Cunha Barbosa. In: Parnaso Brasileiro, de Januário da Cunha Barbosa: prefácios e indices, p. 11-15. 
D'ondas de contradições,

Ninguém soletre feições,

Que sempre se há de enganar;

Das caras a corações

Há muitas léguas que andar.

Joaquim Norberto organizou a primeira coleção completa das obras do poeta. Sua edição foi criticada, mas é preciso levar em consideração as condições em que trabalhou o pesquisador do século XIX: a não citação das fontes consultadas era prática corrente no Brasil (e não só no Brasil...) daquele tempo; o preconceito segundo o qual determinados temas (como a expressão de pontos de vista contrários à independência dos países americanos) manchariam a glória dos autores levou à exclusão de um poema (que, aliás, anda perdido até hoje); e a crença na firmeza das relações entre a base biográfica e os conteúdos dos poemas era característica, se não de todos os historiadores da época, do editor de Alvarenga Peixoto.

À edição de Norberto seguiu-se, em 1956, a de Domingos Carvalho da Silva, que suprimiu poemas por razões de pura opinião: num dos casos o poema estava incompleto (mas era o único autógrafo literário do poeta - por isso, peça importantíssima); em outro, por julgar ser o poema mais adequadamente atribuível a Bárbara Eliodora do que a Alvarenga. Os poemas excluídos por ele foram reintegrados à obra do poeta por Rodrigues Lapa.

\section{O texto: tradição impressa}

O poema cujo primeiro verso é "Bárbara bela" não tem sido objeto de polêmica quanto à autoria. O nome de Bárbara Eliodora, a grandeza do mito que se ergueu em torno de sua experiência, o fato de ela ter sido casada com o poeta e mãe de seus quatro filhos, o reconhecido talento do próprio Alvarenga, assim como a atribuição do poema a ele nas fontes que o transmitiram, tudo isso confere credibilidade à autoria. A primeira edição do poema, que traz o número 21 na edição de Rodrigues Lapa, foi feita, segundo informa esse mesmo editor, por Elias Matos, na obra intitulada Miscelânea poética. Ele trazia, nesta edição, por rubrica inicial, os seguintes dizeres: "De Inácio José de Alvarenga, estando

6. ELIODORA. In: OLIVEIRA. História da literatura mineira, p. 89. (Em grifo na edição consultada).

7. Cf. LAPA. Vida e obra de Alvarenga Peixoto, p. LVII-LVIII. 
preso, à sua mulher". ${ }^{8}$ Nas edições das obras completas de Norberto e de Carvalho da Silva, essa rubrica tornou-se mais precisa: "A D. Bárbara Eliodora, sua esposa, remetida do cárcere da Ilha das Cobras". ${ }^{9}$ Rodrigues Lapa não admite que a lira tivesse sido escrita na prisão. Diz ele, em nota aos versos 11-14:

Não é natural que se pudesse dizer isto ["Por entre as penhas / de incultas brenhas / cansa-me a vista / de te buscar"] da reclusão da Ilha das Cobras, onde não havia nem penhas nem incultas brenhas; menos natural é ainda que se referisse à cercadura de montanhas que cinge a cidade do Rio como supôs J. P. Xavier da Veiga, Efemérides mineiras, IV, $56 .^{10}$

A propósito dessas interpretações, procuraremos demonstrar, com base na análise do poema, que, embora Rodrigues Lapa tenha o mais forte argumento, não deixam os românticos, pelo menos em parte e ao modo deles, de ter a sua razão.

Devido a essas diferenças, o poema tem circulado em antologias sob diferentes formas, no tocante à rubrica inicial. Sérgio Buarque de Holanda, que o transcreveu da edição de Norberto, adotou a rubrica inicial daquele editor. ${ }^{11}$ Outros, como Péricles Eugênio da Silva Ramos, tiraram-lhe a rubrica - sem dar-lhe o número 21 de Lapa. ${ }^{12}$ Outros ainda, como Alexandre Pinheiro Torres, conservam-lhe o número 21 dado por Lapa. ${ }^{13}$ Deve-se ressaltar, no entanto, que este último compilador reproduz todos os 33 poemas de Alvarenga Peixoto reunidos por Rodrigues Lapa.

Mas não é apenas a rubrica inicial que varia nesse poema notável: seu refrão também oscila - ora aparece, ora não aparece. Péricles Eugênio da Silva Ramos observa que Norberto "suprimiu o estribilho, sem dizer por que, mas sem dúvida por desconvir à circunstância da 'prisão'." " Domingos Carvalho da Silva o restabeleceu, ${ }^{15}$ e Lapa o integrou definitivamente ao poema, embora lhe fizesse a seguinte observação restritiva: "Um pouco misterioso o sentido dêstes

8. Cf. LAPA. Vida e obra de Alvarenga Peixoto, p. 30-31. A edição da Miscelânea poética, segundo Lapa, foi publicada, no Rio de Janeiro, em 1853, e o poema encontra-se nas páginas 146-147.

9. Cf. PEIXOTO. Obras poéticas, coligidas e anotadas por Joaquim Norberto de Sousa Silva, p. 223-224; PEIXOTO. Obras poéticas, com introdução e notas de Domingos Carvalho da Silva, p. 60-61.

10. LAPA. Vida e obra de Alvarenga Peixoto, p. 30.

11. Cf. HOLANDA. Poetas brasileiros da fase colonial, p. 286-287.

12. Cf. RAMOS. Poesia do ouro: os mais belos versos da "Escola Mineira", p. 147-148.

13. TORRES. Antologia da poesia brasileira, v. 1, p. 381-382.

14. RAMOS. Poesia do ouro: os mais belos versos da "Escola Mineira", p. 148.

15. Cf. PEIXOTO. Obras poéticas, Introdução e notas de Domingos Carvalho da Silva, p. 60-61. 
dois versos; mas talvez se possa ver nêles uma alusão às relações irregulares entre o ouvidor e Barbara Eliodora." ${ }^{16}$ Vê-se, pela justificativa apresentada, que o filólogo português se deixara impressionar pelo modo como se desenvolveu a relação entre Alvarenga Peixoto e Bárbara Eliodora, que tiveram a primeira filha antes do casamento. Diversos indícios apontavam para a repercussão negativa do acontecimento na São João del Rei do século XVIII:

Num meio acanhado como o de São João del-Rei, o caso devia ter suscitado enorme escândalo. As pessoas do ouvidor [Dr. José da Silveira e Sousa, pai de Bárbara Eliodora] e do advogado [Alvarenga Peixoto] foram alvo de críticas acerbas e insinuações maldosas, transmitidas em pasquins que circulavam nas ruas, processo usado na crônica escandalosa da época. Dizia-se que o Dr. José da Silveira e Sousa, já entrado em anos, valia-se das filhas, de sua mocidade e formosura, para conseguir as suas pretensões. ${ }^{17}$

Sucede com o refrão o mesmo que com a rubrica inicial. O poema se apresenta, conforme a edição, com ou sem ele. Sérgio Buarque de Holanda, pela fonte de que se valeu, a edição de Norberto, divulgou-o sem o refrão. Péricles Eugênio, cuja antologia é posterior à edição de Rodrigues Lapa, já traz o poema completo. O refrão do poema, pretende-se demonstrar, está organicamente engastado na estrutura do texto, fazendo todo sentido.

\section{O poema: uma lira e uma intuição}

É este um dos mais belos poemas de amor da literatura brasileira:

Bárbara bela, do Norte estrela, que o meu destino sabes guiar, de ti ausente, triste, somente as horas passo a suspirar.

Isto é castigo que Amor me dá.

16. LAPA. Vida e obra de Alvarenga Peixoto, p. 30, nota aos versos 9-10.

17. LAPA. Vida e obra de Alvarenga Peixoto, p. xxxiv. (Grifos do autor.) 


\begin{abstract}
Por entre as penhas
de incultas brenhas

cansa-me a vista

de te buscar;

porém não vejo

mais que o desejo,

sem esperança

de te encontrar.
\end{abstract}

$$
\begin{aligned}
& \text { Isto é castigo } \\
& \text { que Amor me dá. }
\end{aligned}
$$

Eu bem queria

a noite e o dia

sempre contigo

poder passar;

mas orgulhosa

sorte invejosa

desta fortuna

me quer privar.

$$
\begin{aligned}
& \text { Isto é castigo } \\
& \text { que Amor me dá. }
\end{aligned}
$$

$\mathrm{Tu}$, entre os braços,

ternos abraços

da filha amada

podes gozar.

Priva-me a estrela

de ti e dela,

busca dois modos

de me matar.

$$
\begin{aligned}
& \text { Isto é castigo } \\
& \text { que Amor me dá. }
\end{aligned}
$$

Diante do poema e de seu mistério, a primeira pergunta que nos ocorre diz respeito à forma. Joaquim Norberto o classifica como "lira", 19 Rodrigues Lapa confirma discretamente a classificação: "Pelas razões que damos em nota, não é admissível que a lira fôsse composta na prisão." ${ }^{20}$ Efetivamente,

18. PEIXOTO. In: LAPA. Vida e obra de Alvarenga Peixoto, p. 30-31.

19. Cf. SILVA. In: PEIXOTO. Obras poéticas, p. 215-224.

20. LAPA. Vida e obra de Alvarenga Peixoto, p. 30. 
trata-se de uma lira, como outra - "Marília bela" - do próprio poeta, a que Rodrigues Lapa atribuiu o número 18, e como as de Gonzaga.

Proveniente da Itália, a estrofe empregada por Bernardo Tasso numa poesia - Opastori felici - dos seus Amori, embora utilizada por Garcilaso de la Vega, em apenas um poema, A la flor de Gnido, fez fortuna na poesia espanhola do século XVI, pois foi empregada por Fray Luis de León e San Juan de La Cruz. Sobre essa sequência histórica, diz, como que atônito, Dámaso Alonso:

Por que Garcilaso para sua Flor de Gnido foi fixar-se, exatamente, no tipo [estrófico] que no volume de 1534 [de Bernardo Tasso] só aparecia uma vez? Caprichosa e fértil casualidade! Porque uma só vez o usou também Garcilaso, mas este fato ia ter grande transcendência em poesia espanhola. ${ }^{21}$

Trata-se de uma estrofe de cinco versos decassílabos e hexassílabos, consoantemente rimados, com as rimas dispostas segundo o esquema aBabB. Segundo Rudolf Baehr, o nome lira "procede da última palavra do primeiro verso da Canción V (A la flor de Gnido) de Garcilaso":

Si de mi baja lira

Tanto pudiese el son, que en un momento

Aplacase la ira

Del animoso viento

Y la furia del mar y el movimiento.

a
B
b
$B^{23}$

$\mathrm{B}^{23}$

E sobre o destino dessa forma estrófica em Espanha, diz ainda o mesmo Dámaso Alonso:

Era exatamente na Espanha onde, com um amplo desenvolvimento, havia de vingar a única coisa verdadeiramente importante que iam produzir na Europa as industriosas tentativas de Bernardo Tasso: através de Garcilaso (e também talvez diretamente), a ode de Fray Luis de León; e através de Garcilaso e de Fray Luis, a de San Juan de la Cruz. Duas grandes condensações de espírito, duas altas labaredas iluminadoras sobre a cinzenta tonalidade geral (horaciana ou petrarquesca) da poesia européia do século XVI. ${ }^{24}$

21. ALONSO. Sobre as origens da lira. In: Poesia espanbola, p. 461.

22. BAEHR. Manual de versificación española, p. 373.

23. GARCILASO. Apud BAEHR. Manual de versificación española, p. 372.

24. ALONSO. Sobre as origens da lira. In: Poesia espanhola, p. 462-463. 
Resultou a lira das inúmeras tentativas de Bernardo Tasso para alcançar uma estrutura móvel, que lhe permitisse as rápidas transições e evasões possíveis no modelo latino de Horácio. Segundo esse espírito, foi natural que em torno dessa estrofe surgissem outras, aparentadas a ela, com número variável de versos (de quatro a seis) e com combinação variada de decassilabos inteiros e quebrados.

Em língua portuguesa, Filipe Nunes menciona dois modelos: o descrito acima e o empregado por Jorge de Montemaior, quintilha com três versos inteiros (o primeiro, o terceiro e o quinto) e dois quebrados (o segundo e o quarto). Diz ele que se chamam liras por serem cantados à viola.

Da designação de uma estrofe à designação de uma forma poética o passo parece ter ocorrido segundo a lógica da explicação dada por António Coimbra Martins:

É possível que a característica comum a essas estrofes diferentes tenha sido a sua aptidão para se cantarem à viola, de que fala Filipe Nunes, ou, pelo menos, a sua grande musicalidade na dicção. Isso explicaria o nome de liras que Tomás Gonzaga deu aos poemas da sua Marília de Dirceu, dos quais dizia Teófilo Braga que deviam ser acompanhados da competente música, quando se fizesse a edição monumental da obra (Filinto Elísio e os dissidentes da Arcádia, Porto, 1901, p. 604, nota). ${ }^{26}$

No Brasil, segundo Massaud Moisés, graças ao influxo da música popular brasileira, a lira "tornou-se 'uma canção em que se repete de ordinário um estribilho ao fim de cada estrofe' (Manuel do Carmo, Consolidação das Leis do Verso, 1919, p. 275)." ${ }^{27}$

A característica fundamental nessa lira de Alvarenga Peixoto, que a sugere feita para o canto, é justamente a existência do estribilho. Embora a lira tivesse alcançado, nos poetas da Escola Mineira, graças à obra de Gonzaga, grande variabilidade e enorme plasticidade - tanto nos metros empregados pelo poeta como no número de versos por estrofe -, a marca distintiva da forma parece ser a ocorrência frequente de refrão (mas, também nesse particular, dispunha o poeta de grande liberdade).

25. Cf. NUNES. In GOMES. Filipe Nunes: Arte poética (um tratado maneirista de métrica), p. 118.

26. MARTINS. Lira. In: COELHO. Dir. Dicionário de literatura: Literatura brasileira; Literatura portuguesa; Litertura galega; Estilística literária, v. 2, p. 535.

27. MOISÉs. Dicionário de termos literários, p. 305-306. 
$\mathrm{Na}$ primeira parte das liras de Gonzaga encontramos estrofes que variam de 4 a 13 versos - e na segunda parte há uma lira com estrofes de três versos. Quanto ao metro, Gonzaga empregou com frequência o tetrassílabo, que é o verso mais curto de suas liras; mas empregou, também, versos de cinco, seis, sete e dez sílabas. Das 33 liras da primeira parte, nada menos que sete apresentamse compostas exclusivamente em versos tetrassílabos. E quanto ao refrão, ele ocorre (salvo engano nosso) em oito das 33 liras da primeira parte - não é tão frequente quanto as considerações teóricas nos fariam esperar. Naturalmente, o que vai dito aqui baseia-se apenas em parte da obra que consagrou essa forma poética em língua portuguesa - a Marília de Dirceu, de Tomás Antônio Gonzaga.

A lira 21 (empregaremos o número que lhe foi dado na edição de Lapa, na falta de um título), de Inácio José de Alvarenga Peixoto, é um poema de amor e de dor - não exatamente da dor do amor enquanto sentimento que causa sofrimento por sua intensidade, mas da dor da separação. Ela está composta em versos tetrassílabos, que ao tempo do poeta se chamavam pentassílabos. Apresenta quatro estrofes de oito versos e um dístico por refrão. O esquema de rimas consoantes da primeira estrofe, aabcddec, repete-se nas três subsequentes e nos aponta uma outra regularidade interna a cada estrofe: os versos 3 e 7 são soltos - embora apresentem algum tipo de correspondência rímica com os versos correspondentes das outras estrofes. Há, ainda, na primeira estrofe, rima toante entre o verso 3 e o primeiro verso do refrão; como há rima, também toante, entre os versos 4 e 8 e o segundo verso do refrão. A maior parte das rimas é grave, apenas os versos 4 e 8 apresentam rima aguda - e esses versos rimam todos entre si, em todas as estrofes. Esse conjunto de características parece-nos indicar a divisão de cada estrofe em duas partes: uma primeira, que compreende os quatro primeiros versos, e uma segunda, que abarca os quatro versos seguintes.

Se o verso de quatro sílabas tinha o nome de pentassílabo no tempo em que o poema foi escrito, isso não lhe tira a característica fundamental de possuir dois acentos fortes. O nome atual de tetrassílabo the vem do fato de sua quarta sílaba ser necessariamente acentuada. E, como no verso português, quando "colidem duas sílabas fortes de vocábulos diferentes, sem pausa separativa, atenua-se a intensidade da primeira, que terá valor de sílaba fraca”, ${ }^{28}$ restam ao verso de quatro sílabas duas outras possibilidades de acento: ou na segunda ou na primeira sílaba. Há, ainda, a possibilidade de as três primeiras sílabas do verso

28. ALI. Versificação portuguesa, p. 13. 
serem todas átonas, mas essa possibilidade não ocorre nessa lira de Alvarenga. As possibilidades rítmicas do verso - tão restritas! - foram utilizadas pelo poeta sem que a monotonia se impusesse à composição e, queremos crer, ainda deixam liberdade ao leitor para determinar a posição de alguns acentos, quando ele é facultativo (numa ou noutra das duas sílabas - primeira ou segunda).

Resumindo: um poema de amor, em que o poeta se dirige direta e imaginariamente à amada ausente - duas pessoas; quatro estrofes de oito versos cada uma; um refrão composto por dois versos; cada verso com dois acentos fortes; cada estrofe divisível em duas partes. Todo o poema parece composto em torno do número dois: dois amantes, dois acentos em cada verso, dois versos no refrão, duas partes e dois versos soltos em cada estrofe. É natural que um poema de amor se organize assim, ainda que amante e amada estejam apartados - o que, aliás, os torna justamente dois, um apartado do outro.

O problema da separação parece-nos o tema central do poema. Não se trata apenas de um poema de amor e de saudade alimentada pela esperança, mas de um poema em que predomina a dor da separação irremediável. Se o poema não foi composto na Ilha das Cobras, como pretende Rodrigues Lapa, e é provável que o não tenha sido, há algo na imaginação lírica do poeta que é prenúncio do futuro incerto (e agora, passados tantos séculos, já certo).

\section{Uma semelhança com Gonzaga}

Antonio Candido afirmou que "Gonzaga é dos raros poetas brasileiros, e certamente o único entre os árcades, cuja vida amorosa tem algum interesse para a compreensão da obra." ${ }^{30}$ é certo que o analista aí se refere ao conjunto da obra, e para o conjunto da obra a afirmação é verdadeira. Aplicada a ideia ao detalhe, entretanto, se considerarmos a lira 21 de Alvarenga, podemos transferir para ela o mesmo raciocínio. Na análise de uma lira de Gonzaga, diz, ainda, o mesmo Antonio Candido: "Se ignorarmos a vida de Gonzaga, é certo que a leitura basta para fruirmos o enunciado no nível ostensivo, em todo o seu encanto rústico. Mas tudo fica mais claro e significativo se conhecermos a natureza das vantagens cuja

29. Cf. as possibilidades rítmicas nos quadros organizados por PROENÇA. Ritmo e poesia, p. 92-95.

30. CANDIDO. Naturalidade e individualismo em Gonzaga. In: Formação da literatura brasileira, v. 1, p. 115. 
perda o falso pastor lamenta..." ${ }^{31}$ Mudados os termos, o mesmo se pode dizer de Alvarenga, a propósito dessa lira dirigida a dona Bárbara: se ignorarmos sua vida, é certo que a leitura basta para fruirmos o enunciado no nível ostensivo, em todo o seu encanto; mas tudo fica mais claro e significativo se conhecermos o destino que a sorte reservou ao poeta e a sua mulher. Agora, passados os acontecimentos, já conhecemos o destino que tiveram os amantes - e com isso o entendimento proposto para o poema ganha extraordinária força. Esse mesmo entendimento estava implícito nas interpretações românticas do poema, que situaram o poeta na Ilha das Cobras, para ajustar o poema a seu sentido mais profundo.

É da tradição a associação da figura do poeta à do vate, ou seja, do vidente, que faz vaticínios, profecias. "Vate" - registra Bluteau - "He palavra latina de vates, que he Poeta ou Adevinho." Já em latim a palavra vates - que significava "adivinho, oráculo, ministro de um Deus, profeta, vidente" - se usava para "poeta". Não são raros os poetas que tiveram a intuição do futuro - Ezra Pound os chamava de "antenas da raça". 33 Poderíamos dizer que a lira 21, de Alvarenga Peixoto, participa desse grupo privilegiado de poesias que contém em si um agouro cifrado.

Caso semelhante se deu com Gonzaga. Rodrigues Lapa, quando the editou criticamente a obra, a propósito da ordenação que nela deu aos poemas, apoiou-se no seguinte argumento:

O melhor critério, quanto a nós, é o da seriação cronológica, que tem a vantagem de conservar em geral a ordem antiga das Liras. A numeração seguida torna-se dêsse modo um ponto de referência mais cômodo e menos complicado. ${ }^{34}$

E que poema escolheu Lapa para ocupar o primeiro lugar na série de Gonzaga? Justamente um daqueles oraculares (talvez o único em toda a obra), mas cujo valor premonitório só pôde ser reconhecido depois de consumados os destinos de Dirceu e Marília:

31. CANDIDO. Uma aldeia falsa. In: Na sala de aula: caderno de análise literária, p. 34 .

32. BLUTEAU. Vocabulário português e latino, v. 8, p. 374.

33. POUND. Abc da literatura, p. 77.

34. LAPA. In: GONZAGA. Poesias; Cartas chilenas, p. xxxvir. (Grifos do autor.) 


\begin{abstract}
Num fértil campo do soberbo Douro, dormindo sôbre a relva, descansava, quando vi que a Fortuna me mostrava, com alegre semblante, o seu tesouro.
\end{abstract}

De uma parte, um montão de prata e ouro com pedras de valor o chão curvava; aqui um cetro, ali um trono estava, pendiam coroas mil de grama e louro.

- Acabou-se - diz-me então - a desventura: de quantos bens te exponho qual te agrada, pois benigna os concedo, vai, procura.

Escolhi, acordei, e não vi nada: comigo assentei logo que a ventura nunca chega a passar de ser sonhada. ${ }^{35}$

O soneto vale por um anúncio: está aí o destino futuro do poeta - cuja ventura amorosa com a pastora Marília, nos bosques da Arcádia, nunca chegou a passar de ser sonhada. Quis o destino que às vésperas do casamento fosse o poeta preso e degredado para Moçambique, acusado do crime de inconfidência, ou seja, de infidelidade para com a coroa.

Esse soneto havia recebido o número 2, dado pelo mesmo Lapa, na edição de $1942 .^{36}$ Nesta edição, o filólogo conservara os poemas na ordem em que apareciam nas primeiras edições, embora lhes mudasse os números, tentando reconstituir a cronologia das composições. Na edição de 1957, ele os pôs na ordem de sua própria numeração, e, nisso, alterou o número do soneto 2 para 1. Desse pequeno detalhe ele não dá notícia, mas não se pode deixar de supor que a secreta razão seja a que foi aqui apontada. Sobre a mudança total na ordem de apresentação dos poemas, justificou ele:

A edição que fizemos da "Obras Completas de Tomás Antônio Gonzaga" em 1942, em plena guerra, saiu com as imperfeições devidas a uma tão excepcional situação. Entre essas imperfeições avultava sobretudo a caótica numeração das poesias, que, tendo submetido a um critério possivelmente

35. GOnZaga. Poesias; Cartas chilenas, p. 3.

36. GONZAGA. Obras completas, p. 178. 
cronológico, apareciam agora [em 1942] na disposição antiga, mas numeradas à moderna.

Resta anotar que nas edições primeiras de Marilia de Dirceu as liras vinham numeradas em algarismos romanos, e recomeçadas do número I a cada uma das três partes. Na numeração "à moderna”, Lapa adotou os algarismos arábicos.

\section{Retornando a Alvarenga, d. Bárbara Eliodora e ao poema}

Sobre Bárbara Eliodora, escreveu Cecília Meireles no Romanceiro da Inconfidência:

Mas a sorte é diferente

de tudo que se imagina.

E eu vejo a triste donzela,

toda em lágrimas e ruína,

clamando aos céus, em loucura,

sua desditosa sina.

Perde-se quanto se adora,

Dona Bárbara Eliodora! ${ }^{38}$

A loucura de Bárbara Eliodora não só passou à literatura, o que é justo; mas impregnou também a história. Sílvio Romero, logo em seguida à transcrição dos termos da sentença que condenou Alvarenga Peixoto à morte (pena que foi comutada pela de degredo) e declarou infames seus filhos e netos, assim como o confisco de seus bens, escreveu na História da literatura brasileira: "Com este golpe Maria Iphigenia morreu de vergonha e desalento e Barbara Heliodora enlouqueceu!..." A vinculação dos sucessos da Inconfidência Mineira à doença mental de que d. Bárbara sofreu no final da vida (ela morreu em 1819, aos 70 anos de idade) e da qual há, segundo Martins de Oliveira, documentação expressa, é negada pelo historiador da literatura mineira: a doença estaria, sim, de acordo com ele, ligada ao "assassinato de um filho, tragédia que lhe trouxe profundo abalo moral".

37. LAPA. In: GONZAGA. Poesias; Cartas chilenas, p.XXXVII. (Grifos do autor.) 38. MEIRELES. Romanceiro da Inconfidência. In: Poesia completa, v. 1, p. 944. (Grifos da autora.)

39. ROMERO. História da literatura brasileira, v. 1, p. 236.

40. OLIVEIRA. História da literatura mineira, p. 93. 
Mas retornemos à lira 21: cada estrofe dela apresenta duas partes, e em cada uma há um verso solto.

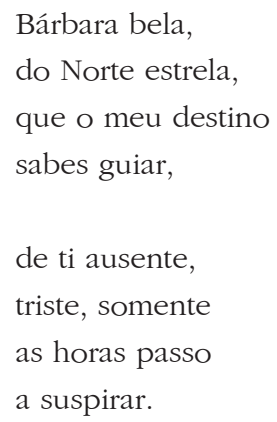

As duas partes se unem fortemente pela rima dos versos quarto e oitavo, únicas rimas agudas da estrofe. A simetria entre os versos soltos ajuda na composição harmônica do todo: na primeira metade, "destino" não rima com qualquer outra palavra; na segunda, "passo" está, no tocante a esse aspecto, em idêntica situação. E no interior de cada uma das partes, os versos soltos encontram-se na mesma posição: dividindo-se a oitava em dois quartetos, o terceiro verso de cada quarteto fica solto.

Para além dessas simetrias no plano formal exterior da estrofe, há ainda mais no plano da significação. Na primeira metade da estrofe, isto é, nos primeiros quatro versos, o poeta se dirige diretamente a Bárbara - o primeiro verso é um contido vocativo, que não traz a usual interjeição "ó", também por razões métricas. O segundo verso é um aposto, em que se declara ser ela a "estrela do norte", ou seja, a estrela polar, assim chamada por estar a pequena distância do polo norte, aparecendo quase imóvel no céu e indicando a direção norte. Esse sentido de "direção", "rumo", transmitiu-se à própria palavra "norte", que o absorveu por figuração. A "estrela do norte" tem no verso sentido figurado: Bárbara é o "norte" do poeta, é ela que dá sentido, rumo e significação ao que ele faz. No espaço estreito dos primeiros quatro versos a palavra "destino" aparece com esse sentido, digamos, "leve" - de rumo, de norte, de fim. Entretanto, essa é a mesma palavra perdida no esquema de rimas do poema; a palavra que lhe equivale, ou seja, que ocupa sua posição, na segunda metade da estrofe, é a forma verbal do presente do indicativo "passo" - que tem sentido de ação permanente, ou reiterada. A idéia de reiteração é reforçada pela presença do 
verbo "suspirar", que fecha a estrofe. Como o som as desune, o sentido as afasta: o destino é futuro, o "suspirar" é presente.

Ainda com relação à rima e à palavra "destino", é preciso atentar para um dado importante: ela rima toantemente com "castigo", primeiro verso do refrão. E, ao ser repetido ao longo da lira, o "castigo" do refrão arrasta consigo a ideia de "destino", que rima com ele. E destino é coisa futura, está para acontecer. Será castigo, que o poeta no refrão atribui a Amor, figura alegórica que, sabemos, é cega, brincalhona e irresponsável. Nesse caso, há de fazer a palavra "castigo" com a palavra "destino" o que dizia Sêneca fazia com as pessoas o destino: volentem ducunt fata, nolentem trabunt - ou seja, os que querem o destino conduz, os que não querem ele arrasta.

Começa a fazer sentido o refrão do poema, tão incrível que Joaquim Norberto julgou melhor suprimi-lo, ao passo que Rodrigues Lapa disse dele estas palavras: "Um pouco misterioso o sentido dêstes dois versos; mas talvez se possa ver nêles uma alusão às relações irregulares entre o ouvidor e Barbara Eliodora." ${ }^{41}$

O que salta à vista, na primeira metade da estrofe, é a segunda pessoa gramatical, o destinatário do texto, a amada do poeta. Ela ocupa integralmente os dois primeiros versos, e os dois seguintes atribuem-lhe o papel de "guia" do poeta.

Na segunda metade da estrofe, o poeta volta-se para si mesmo, para sua situação de isolamento. Os seus versos constituem uma unidade sintática, cujos termos invertidos dão à estrofe e ao poema a sua musicalidade peculiar e bem marcada: "na tua ausência, triste, passo as horas somente a suspirar". O advérbio "somente", além de seu valor próprio de advérbio de modo, compondo com "triste" um verso inteiro ("triste, somente"), evoca o valor semântico do termo que o compõe ("só", originalmente "sola"), valendo por um "sozinho". A preferência pelo advérbio parece corresponder às observações de Harri Meier sobre essa categoria de qualificativos - observações "que atribuíram a esta forma um lugar especial para exprimir acontecimentos sofridos pelo indivíduo ou que lhe foram impostos" ${ }^{42}$

A divisão da estrofe em duas partes, constatada no exame da forma primária (ou externa), encontra seu equivalente no plano da situação emocional expressa no poema: a primeira metade corresponde à presença de Bárbara nos versos; a segunda, ao voltar-se do poeta sobre si próprio. Em outras palavras: na primeira metade, o foco é posto na segunda pessoa do discurso; na segunda, o foco é posto na primeira. No caso dessa estrofe, as duas partes se articulam

41. LAPA. Vida e obra de Alvarenga Peixoto, p. 30, nota aos versos 9-10.

42. MEIER. Adjetivo e advérbio. In: Ensaios de filologia românica, p. 86. 
sintaticamente por meio de uma vírgula, numa espécie de continuum, e a estrofe se compõe e se estrutura como um todo unitário.

Outro aspecto ainda digno de reparo é a rima entre os versos quarto e oitavo de todas as estrofes e o segundo verso do refrão: os verbos "guiar/suspirar", "buscar/encontrar", "passar/privar" e "gozar/matar" - todos rimam toantemente com "dá". As estrofes, portanto, assim como a significação geral do poema, parecem bem amarradas ao refrão que percorre a lira e reiteradamente reforça-lhe o sentido. A segunda estrofe, como já foi dito, segue em quase tudo os passos da primeira:
Por entre as penhas
de incultas brenhas
cansa-me a vista
de te buscar;
porém não vejo
mais que o desejo,
sem esperança
de te encontrar.

\section{Isto é castigo}

que Amor me dá.

Aí temos o mesmo ritmo, com algumas opções muito sábias para o recitador não se sentir preso a um esquema único e predeterminado. Sob esse aspecto, conforme já foi dito, há na lira certa abertura à contribuição do leitor. Entretanto, se o sentido deve guiar a prosódia, alguns acentos inusuais ou incomuns são aconselháveis. O pronome "ti", na primeira estrofe, é forma tônica, leva o acento próprio da palavra - naquela estrofe, ainda que situado em sua segunda metade, em que o poeta fala de si, a lembrança de Bárbara é viva; não conhece ainda o leitor a mensagem completa do poema. Na segunda estrofe as coisas começam a mudar: a forma átona aparece duas vezes, nos versos quarto e oitavo - "de te buscar" e "de te encontrar". Nessas duas circunstâncias, a preposição "de", também átona, parece chamar a si o acento, provocando o apagamento da segunda pessoa. Poder-se-ia propor, até, que o primeiro "te" ("de te buscar") fosse acentuado, ao passo que o segundo não o fosse ("de te encontrar") - realizando, no interior da estrofe, o progressivo apagamento/afastamento da segunda pessoa. 
Quanto à divisão da estrofe em duas metades, ela se acentua: graficamente as duas metades se separam agora por ponto-e-vírgula e, sintaticamente, o nexo se faz com "porém", conjunção adversativa, que de algum modo opõe uma parte à outra. Na primeira parte, é Bárbara o que busca o olhar do poeta por entre as penhas; na segunda, o que aparece é o desesperançado poeta - que não a encontra. Também nessa estrofe, "vista", palavra sem rima no corpo da estrofe, rima toantemente com "castigo".

O "castigo" que o "destino" reserva ao poeta começa a acrescentarse de sentido: a "vista" se cansa, não encontra o objeto buscado; e a "esperança" começa a dar lugar à desesperança.

$\mathrm{Na}$ terceira estrofe o processo continua e confirma o que se disse:

$$
\begin{aligned}
& \text { Eu bem queria } \\
& \text { a noite e o dia } \\
& \text { sempre contigo } \\
& \text { poder passar; } \\
& \text { mas orgulhosa } \\
& \text { sorte invejosa } \\
& \text { desta fortuna } \\
& \text { me quer privar. }
\end{aligned}
$$

Isto é castigo

que Amor me dá.

Novamente, na primeira metade o poeta conduz seu pensamento à amada; e, na segunda, volta-se para si mesmo. Outra vez as duas partes da estrofe se separam por ponto-e-vírgula, ganhando cada metade certa autonomia sintática e de significação. O verso solto da primeira metade não apenas rima consoantemente com "castigo"; a palavra que rima, "contigo", apresenta em suas consoantes (na sequência c-t-g) um forte apoio consonantal à rima. Associam-se de forma muito forte o "castigo" e a pessoa a quem se dirige o poeta: dona Bárbara Eliodora.

Em relação à estrofe anterior, a segunda parte desta realiza um salto da condição particular do poeta à condição geral da humanidade - "sorte", nessa passagem, designa o famigerado "destino". Também nessa passagem, "fortuna" é sinônimo de "destino".

Por fim, a última estrofe completa, em sua forma, a exposição da fatalidade que está reservada ao poeta: 


\begin{abstract}
$\mathrm{Tu}$, entre os braços, ternos abraços da filha amada podes gozar.

Priva-me a estrela de ti e dela, busca dois modos de me matar.
\end{abstract}

Isto é castigo que Amor me dá.

Em tudo a estrofe se parece com as outras; mas delas se distingue num ponto de vital importância para o sentido global da lira: as duas partes da estrofe se cindiram sintaticamente. A primeira metade, que se refere à amada do poeta, não se comunica mais com a segunda - espaço reservado ao poeta e seu problema. E nessa segunda parte, no próprio plano temático aparece o elemento que identificamos como princípio organizador da estrutura: o número dois. A amada do poeta tem uma filha, que vive com ela em "ternos abraços", ao passo que o poeta se encontra ausente das duas: "priva-me a estrela / de ti e dela / busca dois modos / de me matar." E eis aí o destino com seu quarto nome: "estrela".

O que se pode ler, na forma do poema, é que a separação dos amantes se consolida - não existe a menor possibilidade de retorno, de reconstituição da felicidade perdida. Essa conclusão é de tal modo convincente que os românticos, na crença de que o lirismo reflete diretamente o vivido, localizaram o poeta, ao tempo da composição do poema, na Ilha das Cobras, quando já se sabia réu de lesa-majestade e previa a pena que o esperava. A essa simplificação interpretativa se opôs Rodrigues Lapa, que, ao estudar a biografia do poeta, percebeu-lhe as contínuas ausências do lar, sempre envolvido em negócios pelo interior de Minas. Em nota aos versos 31-34 da lira, diz ele: "Carvalho da Silva considera a poesia incompleta por causa da referência exclusiva à filha, tendo Alvarenga mais 3 filhos. Isto significará apenas que a lira foi composta entre o nascimento da filha e do filho mais velho, digamos, entre 1779 e $1787 .{ }^{43}$ Se erraram os românticos no tocante aos fatos, acertaram na interpretação.

43. LAPA. Vida e obra de Alvarenga Peixoto, p. 31, notas aos versos 31-34. 


\section{Bárbara bela: an Analysis of a Poem by Alvarenga Peixoto}

Abstract: This article analyzes Poem 21 (following Rodrigues Lapa's classification), by the Arcadian poet Alvarenga Peixoto, mostly known by its first line: "Bárbara bela". Besides studying the poem's structure, the present text also evaluates how pertinent was the poem's reception during Romanticism in relation to its most important meaning: that the separation of the poet and his Bárbara is irreversible.

Keywords: Brazilian poetry; Neoclassical poetry; Alvarenga Peixoto.

$$
\text { Referências }
$$

ALI, M. Said. Versificação portuguesa. Rio de Janeiro: Instituto Nacional do Livro, 1948. ALONSO, Dámaso. Sobre as origens da lira. In: Poesia espanhola. Rio de Janeiro: Instituto Nacional do Livro, 1960. p. 458-463.

AUTOS de devassa da Inconfidência Mineira. Belo Horizonte: Governo do Estado de Minas Gerais, 1976-1983. 10v.

BAEHR, Rudolf. Manual de versificación española. Madrid: Gredos, 1989.

BLUTEAU, Rapael. Vocabulário português e latino. Lisboa: Oficina de Pascoal da Silva, 1712-1728. 10v.

CANDIDO, Antonio. Naturalidade e individualismo em Gonzaga. In: Formação da literatura brasileira. Belo Horizonte: Itatiaia, 1981. v. 1. p. 114-126.

CANDIDO, Antonio. Uma aldeia falsa. In: Na sala de aula: caderno de análise literária. São Paulo: Ática, 1989. p. 20-37.

GONZAGA, Tomás Antônio. Obras completas. Ed. crítica de Rodrigues Lapa. São Paulo: Nacional, 1942.

GONZAGA, Tomás Antônio. Poesias; Cartas chilenas. Ed. crítica de M. Rodrigues Lapa. Rio de Janeiro: Insituto Nacional do Livro, 1957.

HOLANDA, Sérgio Buarque de. Poetas brasileiros da fase colonial. São Paulo: Perspectiva, 1979 .

LAPA, M. Rodrigues. Vida e obra de Alvarenga Peixoto. Rio de Janeiro: Instituto Nacional do Livro, 1960.

MARTINS, António Coimbra. Lira. In: COELHO, Jacinto do Prado. Dir. Dicionário de literatura: Literatura brasileira; Literatura portuguesa; Litertura galega; Estilística literária. Figueirinhas/Porto: s.e., 1973. 3v.

MEIER, Harri. Adjetivo e advérbio. In: Ensaios de filologia românica. Rio de Janeiro: Grifo, 1973. p. 61-127.

MEIRELES, Cecília. Romanceiro da Inconfidência. In: Poesia completa. Rio de Janeiro: Nova Fronteira, 2001. v. 1. p. 741-969.

MIRANDA, José Américo. O Parnaso brasileiro, de Januário da Cunha Barbosa. In: Parnaso Brasileiro, de Januário da Cunha Barbosa: prefácios e indices. Belo Horizonte: 
Faculdade de Letras da UFMG, 1999. p. 7-29.

MOISÉS, Massaud. Dicionário de termos literários. São Paulo: Cultrix, s.d.

NUNES, Filipe. Arte poetica, e da pintura, e symmetria, com princípios de perspectiva. Lisboa: Pedro Craesbeekc, 1615. In: GOMES, Paulo J. Pedros S. Filipe Nunes: Arte poética (um tratado maneirista de métrica). Coimbra: Universidade de Coimbra. [Dissertação de Mestrado em Literaturas Clássicas apresentada à Faculdade de Letras da Universidade de Coimbra.]

OLIVEIRA, Martins de. História da literatura mineira. Belo Horizonte: Imprensa Oficial, 1963.

PEIXOTO, Ignacio José de Alvarenga. Obras poéticas. Rio de Janeiro: B. L. Garnier, 1865. [Coligidas e anotadas por Joaquim Norberto de Sousa Silva.]

PEIXOTO, Inácio José de Alvarenga. Obras poéticas. São Paulo: Prefeitura do Município de São Paulo, 1956. [Introdução e notas de Domingos Carvalho da Silva.]

POUND, Ezra. Abc da literatura. São Paulo: Cultrix, 1970.

PROENÇA, M. Cavalcanti. Ritmo e poesia. 2 ed. Rio de Janeiro: Simões, s.d.

RAMOS, Péricles Eugênio da Silva. Poesia do ouro: os mais belos versos da "Escola Mineira". São Paulo: Melhoramentos, 1964.

ROMERO, Sílvio. História da literatura brasileira. 2. ed. Rio de Janeiro: H. Garnier, 1902. $2 \mathrm{v}$.

TOPA, Francisco. Quatro poetas brasileiros do período colonial - Estudos sobre Gregório de Matos, Basílio da Gama, Alvarenga Peixoto e Silva Alvarenga. Porto: Edição do Autor, 1998.

TORRES, Alexandre Pinheiro. Antologia da poesia brasileira (do Padre Anchieta a João Cabral de Melo Neto). Porto: Lello \& Irmão, 1984. 3v. 